\title{
Increasing mine train mass by means of improved efficiency of service braking
}

\author{
Oleksii Novytskyi ${ }^{1 *}$, Ihor Taran ${ }^{1}$, and Zhemazhan Zhanbirov ${ }^{2}$ \\ ${ }^{1}$ Dnipro University of Technology, Department of Transportation Management, 19 Yavornytskoho, \\ 49005 Dnipro, Ukraine \\ ${ }^{2}$ Kazakh Academy of Transport and Communications named after M. Tynyshpaev, Almaty, \\ Kazakhstan
}

\begin{abstract}
Methods to increase mine train mass allowable for braking have been studied. Possibility to use rail magnetic brakes to improve efficiency of dynamic braking has been analyzed. Mathematical model of the train braking involving a magnetic rail device to increase locomotive axial load has been proposed. Results of the braking calculations with the use of the modeling results have made it possible to conclude on the fact that a magnetic rail device used to increase locomotive axial load allows improving considerably braking characteristics of a locomotive and increasing mine train mass allowable for braking.
\end{abstract}

\section{Introduction}

Under conditions of global growth of the human needs in resources, a task of efficient operation of mining enterprises becomes rather important [1,2]. Development of more productive, reliable, and safe means to transport rock mass $[3,4]$, personnel, and materials within the production sites is one of the aspects of that task. Along with the transportation means of continuous action [5, 6], different locomotives will be widely used in the near future [7]; though, the locomotives have certain advantages comparing to conveyors, they demonstrate lower productive capacity.

First of all, productive capacity of locomotive transport may be improved by means of the train mass increase. Calculations performed in the context of Western Donbas mines have shown that in terms of standard routes, train mass growth by $10 \%$ results in the hourly productivity gain of a locomotive by $7.4 \%$ while increased average train velocity by $10 \%$ demonstrates only $3.1 \%$ of the productivity gain.

Methods to calculate parameters of locomotive haulage, which are applied in Ukraine, contain such term as "train mass allowable for braking" [8], i.e. the mass at which a train may be stopped by standard braking means of a locomotive within the specified braking path (40 km for freight trains, $20 \mathrm{~m}$ for passenger trains). Value of braking force implemented by a train is the basic factor determining the possibility of a stop and, consequently, allowable train mass. Braking force of the traditional braking types is determined by the adhesion weight of a locomotive and coefficient of wheel-rail adhesion.

\footnotetext{
* Corresponding author: novitskyialex@gmail.com
} 
Technical solutions as for improvement of each factor are rather complicated and costly [9, 10]. Ideas to equip mine cars with brakes have not been developed further as well. At the same time, rail magnetic brakes have been used successfully on rolling stock of rail transport for more than 100 years; those brakes develop additional braking effort, independent from traditional brakes, at the expense of brake unit and rail friction $[11,12]$. Operational practice has proved high efficiency of their application for emergency braking and as the parking brake; however, attempts to use rail magnetic brakes for service braking were not successful. Braking effort of rail magnetic brakes is characterized by the step-like increase in braking force at the moment of brake unit and rail contact from zero up to the maximum value being expedient for emergency braking but not acceptable for service braking. Attempts to develop rail brakes with the possibility to regulate braking force were not successful since the introduction of a magnetic unit of additional devices into the structure resulted in the complicated operation and reduced reliability being unacceptable for braking systems, especially in terms of industrial transport operation.

\section{Statement of the problem}

Nowadays, a number of scientific papers deal with the problems concerning the improvement of braking efficiency in terms of rail transport by means of magnetic braking devices. Topicality of that problem is explained by constant increase in the velocity and mass of trains as well as by the requirements for traffic safety, which are getting more and more stringent.

Author of paper [13] represents the research results as for changes in vertical wheel and braking torque load during the braking process. It has been determined that while locomotive moving, vertical wheel load may vary by $20 \%$ relative to the nominal value effecting the braking torque value. It is also proposed to remove negative impact of wheel load variations by means of application of control systems being rather prospective solution for main-line locomotives but not applicable for mine transport.

Paper [14] represents comparative analysis of the efficiency of different braking systems of rail vehicles. The authors emphasize that the efficiency of braking mechanisms, implementing braking force at the point of wheel-rail contact, depends considerably upon the conditions of that interaction while rail magnetic brakes are less sensitive - thus, they are expedient to be used for emergency braking. Moreover, methodology to calculate braking path is represented; however, that methodology does not allow evaluating the effect of rail magnetic brakes upon the braking parameters.

Studies of the effect of eddy-current magnetic brake parameters upon their braking force, represented in [15] confirm the expediency of magnetic brake use right on the industrial vehicles where velocities are much lower comparing to the main-line transport. That is explained by the fact that the rail brake efficiency decreases along with the increasing initial braking velocity.

Results of the comparative analysis of the efficiency of rail magnetic brakes of different designs [16] prove high efficiency of rail brakes in terms of the velocities being lower than $50 \mathrm{~km} / \mathrm{h}$ which are characteristic for industrial rail transport including underground one. At the same time, area of magnetic brake application is limited by emergency braking; a variant of using magnetic brakes for service braking is not considered. Authors of paper [21], representing the results of studying the effect of braking conditions upon the braking path length, have determined that there is the optimal braking torque for specific braking conditions; in terms of that braking torque, the braking does not result in wheel lock-up providing minimal braking path. According to the opinion of some researchers $[17,18,19]$, a problem of braking path length reducing at the expense of the development of optimal braking torque may be solved only by implementing automated system of braking 
mechanisms control based on state-of-the-art IT solutions.

In general, analysis of current scientific studies concerning the problems of improving the efficiency of rail vehicles braking makes it possible to draw following conclusions:

1) tendencies of increasing train velocity and mass require innovative solutions to provide safe vehicle running, including the improvement of braking systems of a rolling stock;

2 ) in terms of main-line transport, problems of the braking efficiency improvement are solved mainly by means of implementing automated systems of braking mechanisms control which allows reducing the effect of a human factor and applying optimal braking algorithms. Implementation of automated systems of braking mechanisms control requires considerable studies and significant financing for the equipment being justified in terms of main-line railroad transport but not expedient in case of mine rail transport;

3) mathematical models of braking process and methods to improve braking efficiency developed for main-line transport cannot be applied to solve the problems as for improvement of braking characteristics of mine locomotives due to the considerable differences in operating conditions (first of all, train velocity and mass) and more stringent criteria for the braking system efficiency.

Objective of the study is to increase train mass allowable for braking by means of improved efficiency of service braking in terms of simultaneous use of dynamic braking and a magnetic rail device.

To reach the objective, following problems are to be solved:

1) developing a mathematical model of the braking process for a mine locomotive in terms of simultaneous use of standard braking mechanisms and magnetic rail devices to increase the locomotive axial load;

2) modeling a braking process for real operating conditions;

3) quantitative evaluation of the effect of additional load upon the efficiency of standard braking mechanisms and resulting parameters of the locomotive transport operation.

\section{Materials of the research}

Currently, dynamic motor braking, under which braking force is formed at the point of wheel-rail contact, is the only technique to reduce velocity of a mine train.

In terms of dynamic braking, braking force formed at the point of wheel-rail contact, is determined by the value of a braking moment and limited by the adhesion conditions. Braking force implemented by a locomotive during dynamic braking is [12, 13]:

$$
F_{t}=\frac{\sum_{i=1}^{n} M_{i}}{R},
$$

where $M_{i}$ is braking torque applied to the $i^{\text {th }}$ wheel; $R$ is radius of a wheel.

Expression to determine maximum braking force according to the adhesion condition is as follows:

$$
F_{t \cdot \max }=\sum_{i=1}^{n} N_{i} \cdot \psi
$$

where $F_{t . \max }$ is maximum braking force; $N_{i}$ is vertical load on the $i^{\text {th }}$ wheel; $\psi$ is coefficient of wheel-rail adhesion.

If the breaking torque applied to a wheel is excessive, then braking force will exceed the adhesive force at the point of wheel-rail contact, and a wheel will be blocked. Maximum value of a braking moment may be determined from expression: 


$$
\sum_{i=1}^{n} M_{i}=\sum_{i=1}^{n} N_{i} \cdot \psi \cdot R
$$

It is obvious that the increase in vertical wheel load is the condition of the increased braking torque being safe in terms of wheel lock-up.

One of the variants to solve that problem is to design and construct magnetic rail devices to increase locomotive axial load [21]; specific features of those devices are the possibility to transmit a share of the force of magnetic attraction from a magnetic unit on the locomotive axis. Principally, additional axial load may result in the increased efficiency of both service motor braking and emergency wheel and shoe braking. However, quantitative evaluation of the device efficiency was not performed due to the nonavailability of adequate mathematical model of the locomotive braking process in terms of simultaneous use of standard braking mechanisms and magnetic rail devices to increase locomotive axial load.

Sections of magnetic unit 1 creating force of magnetic attraction at the moment of contact with the rail are the basic elements of the structure of magnetic rail device to increase locomotive axial load (Fig. 1). Sections are interconnected by means of sliding hinge 2 with the possibility to move along the rail. Sections are raised and lowered with the help of hydraulic drive 4 and hinges 5 . Hinges are fixed on the rigid beam resting upon the locomotive axis.

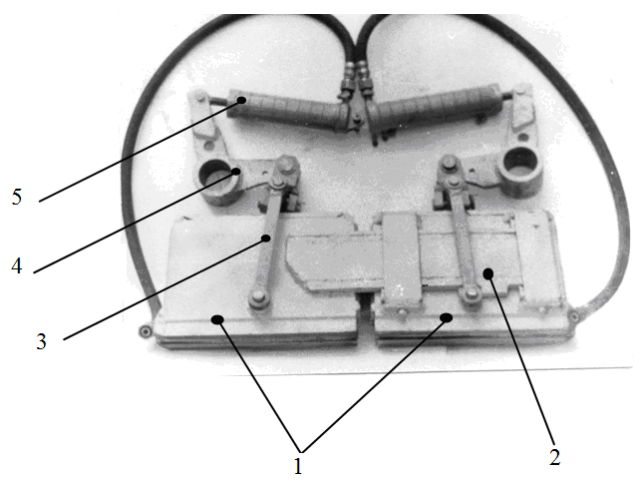

Fig. 1. Magnetic rail device to increase locomotive axial load: 1 -sections of a magnetic unit; 2 - sliding hinge; 3 - inclined thrust; 4 - hinge; 5 -hydraulic drive to bring a magnetic unit up/down.

Principle of the action of a magnetic rail device is as follows: a share of the magnetic attraction force, being the result of the magnetic unit-rail contact, is transmitted through the inclined thrusts and beams onto the locomotive axis that creates additional wheel load. Value of the additional load on the wheels depends upon the force of magnetic attraction of a section to the rail, friction coefficient of a magnetic unit, and angle of thrust inclinations [20, 21, 22].

While elaborating a computational scheme (Fig. 2), parameters of prospective mine electric locomotive AРП10РB were applied; that locomotive is characterized by two braking systems which implement braking effort at the points of wheel-rail contact - a system of dynamic motor braking and wheel and shoe brake.

Mine locomotive may be represented as a discrete nonlinear mechanic system consisting of a body, two wheel pairs, and two magnetic units (each unit includes two sections). It is considered that all the bodies are absolutely rigid since the coefficients characterizing stiffness of wheel pairs, body, and rail brakes are much higher than the corresponding indices for a spring equalizing system. As the locomotive underframe and magnetic units operate with the railway track, such mechanical system as "railway track magnetic rail device - locomotive" should be studied taking into account elastic-dissipative 
characteristics of the railway track. A string of loaded mine cars is connected to the locomotive coupling gear by means of elastic-dissipative connections. Wheels with semiaxes and a cogged wheel of the axial speed transformer (with the reduced masses and inertia moments of other transmission elements) rotate about their proper axes.

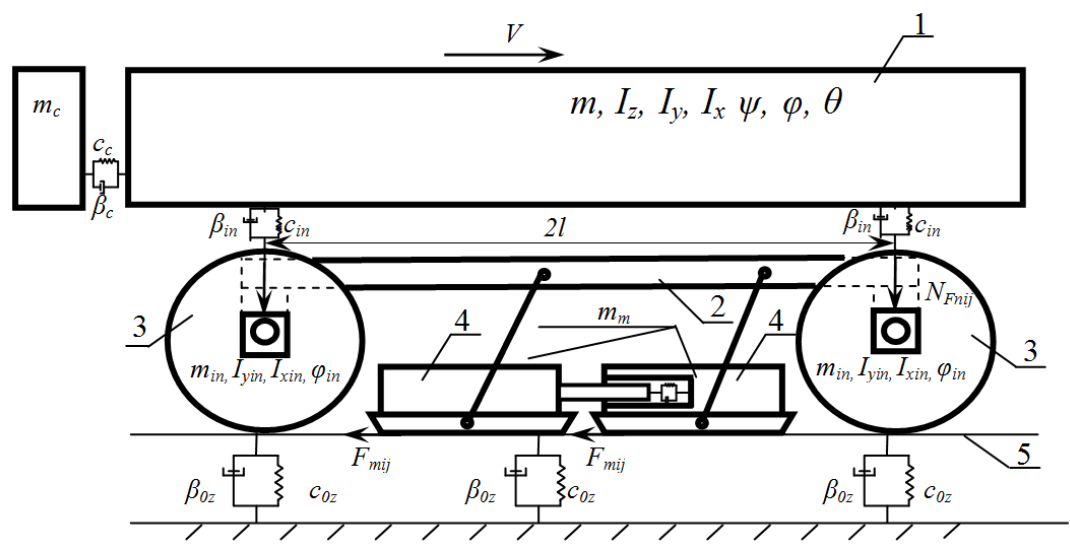

Fig. 2. Computational scheme for a mine locomotive: 1 -body; 2 -rest beam; 3 -wheel pairs; 4 - sections of a magnetic unit; 5 - railway track.

Here and further, following lower indices, which determine belonging of the variable to the object of a mathematical model, are specified to describe variables: in - to the axisbased wheels, elastic and damping elements; $(i=1,2)$, i.e. 1 is to show a wheel pair being the first one towards the head end of a train; $m_{i n}$ - to the sections of magnetic units, i.e. 1 is to show the section being the closest one to the head end of a train; $(i=1,2)$, i.e. 1 is to show the sections being left in the direction of train travel; sin - to the wheel and shoe brake mounted on the $i^{\text {th }}$ pair of the $n^{\text {th }}$ wheel; $o$ - to the base (railway track).

Railway track is considered to be elastic and viscous within the horizontal-transverse and vertical planes.

Well-known and approbated models [24 - 25] are the basis to develop a mathematical model of the braking process of a mine train. There are following considerable differences of the represented model:

- introduction of the additional equations describing displacements of the sections of a magnetic unit of the device to increase the locomotive axial load;

- consideration of the effect of additional axial load and braking force from a magnetic rail device.

While elaborating a mathematical model of the mine train braking, following assumptions are taken:

- a string of mine cars connected to locomotive coupling gear is represented in the form of a single body with the total mass;

- longitudinal travel of the track rails and railway base are not taken into account;

- loads displacing one track rail of the railway line do not effect another one along with the nonavailability of mutual displacements of rails and bases on the contact surface;

- railway track has constant curvature radius, longitudinal and transverse slopes, and gage increase under each wheel pair;

- flow of a share of magnetic attraction force on the locomotive axis does not result in changes in basic parameters of the wheel-rail interaction [26].

In the process of motor breaking, torque is transmitted through the axis to the left (with index1) and right (with index 2) wheels. In this context, their reduced masses at the moment 
of inertia as well as torsional stiffness and dissipation coefficients will be different due to the asymmetric arrangement of a cogged wheel on the wheel pair axis. Following symbols are used in the mathematical model: $F_{i n}$-braking force arising at the contact point of rolling pathways of the rail and $i{ }^{\text {th }}$ wheel, $\mathrm{N} ; W_{x i n}$ - force of longitudinal slip of the $i n^{\text {th }}$ wheel, at the rail contact point, connected with the passing of wheel rolling friction along the rail and friction moments within the rotating elements reduced to the rolling pathway of a wheel, N; $W_{\text {pin }}$ - force of longitudinal slip of a leading wheel occurring during the flange rubbing on the rail while moving within the curvilinear track section, $\mathrm{N} ; W_{y i n}-$ force of longitudinal wheel slip at the point of rail contact while moving within the curvilinear track section, $\mathrm{N} ; Y_{\text {in }}$ - directing force acting from the rail onto the wheel flange while moving within the curvilinear track section, $\mathrm{N} ; P_{\text {in }}$ - directing force acting from the rail onto the rolling pathway of a wheel due to the conicity of wheel bands, $\mathrm{N} ; N_{\text {in }}-$ normal reaction of the rail under a wheel нормальная, $\mathrm{N} ; N_{F \text { in }}$-additional axial load from the action of a magnetic rail device, $\mathrm{H} ; N_{d i n}$ - dynamic force occurring when wheels impact with the rail while passing uneven sections of the surface, $\mathrm{N} ; M_{\text {sin }}$ - braking torque within the wheel and shoe brake, $\mathrm{N} \cdot \mathrm{m} ; m_{c}=n_{v} m_{v}$ - mass of trailed part of the rolling stock, $\mathrm{kg} ; n_{v}$ - number of mine cars within the rolling stock, units; $m_{v}$ - mass of a loaded mine car (in case of mine cars of VG3.3-900 type, it is $56000 \mathrm{~kg}$ according to technical characteristics); $w_{v}$ - specific traveling resistance of a loaded mine car along the straight line, $\mathrm{N} / \mathrm{kg} ; w_{v R}$ - average additional specific traveling resistance of a loaded mine car along the curved line of $R$ radius, $\mathrm{N} / \mathrm{kg}$.

Braking force of the magnetic unit section is determined according to expression:

$$
F_{\text {min }}=Z_{\text {in }} F_{\text {prin }} f_{m}
$$

where $Z_{i n}$ is signal function, sign of switching-in of a specific section of a magnetic unit, it is either equal to zero in terms of switching-off or equal to a unit in terms of switchingon; $F_{\text {pr in }}$ is force of section pressing to the rail, $\mathrm{N} ; f_{m}$ is coefficient of sliding friction of the pole terminals of a section along the rail.

Having performed all the required substitutions, we will obtain following system of 33 differential equations:

$$
\begin{aligned}
& m_{11} \ddot{z}_{11}+\beta_{z}\left(\dot{z}+\dot{z}_{11}\right)+c_{z} z_{11}=G_{11}-N_{11} ; \\
& m_{12} \ddot{z}_{12}+\beta_{z}\left(\dot{z}+\dot{z}_{12}\right)+c_{z} z_{12}=G_{12}-N_{12} ; \\
& m_{21} \ddot{z}_{21}+\beta_{z}\left(\dot{z}+\dot{z}_{21}\right)+c_{z} z_{21}=G_{21}-N_{21} ; \\
& m_{22} \ddot{z}_{22}+\beta_{z}\left(\dot{z}+\dot{z}_{22}\right)+c_{z} z_{22}=G_{22}-N_{22} ; \\
& m_{o y} \ddot{y}_{o 11}+\beta_{o y} \dot{y}_{o 11}+c_{o y} y_{o 11}=W_{y 11}-Y_{11} \cos \gamma_{11}-P_{11} ; \\
& m_{o y} \ddot{y}_{o 12}+\beta_{o y} \dot{y}_{o 12}+c_{o y} y_{o 12}=W_{y 12}-Y_{12} \cos \gamma_{12}-P_{12} ; \\
& m_{o y} \ddot{y}_{o 21}+\beta_{o y} \dot{y}_{o 21}+c_{o y} y_{o 21}=W_{y 21}-Y_{21} \cos \gamma_{21}-P_{21} ; \\
& m_{o y} \ddot{y}_{o 22}+\beta_{o y} \dot{y}_{o 22}+c_{o y} y_{o 22}=W_{y 22}-Y_{22} \cos \gamma_{22}-P_{22}
\end{aligned}
$$


$\left(m-m_{11}-m_{12}-m_{21}-m_{22}\right) \ddot{x}+\frac{g_{0} m i_{p}}{\sqrt{i_{p}^{2}+1}}+\frac{1}{2}\left(-\frac{4 I_{y} \dot{x} \dot{R}_{p}}{R_{p}^{3}}+\frac{2 I_{y} \ddot{x}}{R_{p}^{2}}-\frac{4 I_{z} \dot{x} \dot{R}}{R^{3}}+\frac{2 I_{z} \ddot{x}}{R^{2}}\right)+$

$+\beta_{c}\left(\dot{x}-\dot{x}_{c}\right)+c_{c}\left(x-x_{c}\right)=0$;

$2\left(m_{11} \ddot{z}+m_{12} \ddot{z}+m_{21} \ddot{z}+m_{22} \ddot{z}+4 G_{11}+4 G_{12}+4 G_{21}+4 G_{22}\right)=$

$=2 m \ddot{z}+16 \beta_{z} \dot{z}+2 \beta_{z} \dot{z}_{11}+2 \beta_{z} \dot{z}_{12}+2 \beta_{z} \dot{z}_{21}+2 \beta_{z} \dot{z}_{22}+8 c_{z} z$;

$I_{y 11} \ddot{\varphi}_{11}+\beta_{\varphi 11}\left(\dot{\varphi}_{11}-\dot{\varphi}_{1}\right)+c_{\varphi 11}\left(\varphi_{11}-\varphi_{1}\right)=r\left(F_{11}+W_{x 11}\right)-M_{s 11}$;

$I_{y 12} \ddot{\varphi}_{12}+\beta_{\varphi 12}\left(\dot{\varphi}_{12}-\dot{\varphi}_{1}\right)+c_{\varphi 21}\left(\varphi_{12}-\varphi_{1}\right)=r\left(F_{12}+W_{x 12}\right)-M_{s 12}$;

$I_{y 21} \ddot{\varphi}_{21}+\beta_{\varphi 21}\left(\dot{\varphi}_{21}-\dot{\varphi}_{2}\right)+c_{\varphi 21}\left(\varphi_{21}-\varphi_{2}\right)=r\left(F_{21}+W_{x 21}\right)-M_{s 21}$;

$I_{y 11} \ddot{\varphi}_{22}+\beta_{\varphi 22}\left(\dot{\varphi}_{22}-\dot{\varphi}_{2}\right)+c_{\varphi 22}\left(\varphi_{22}-\varphi_{2}\right)=r\left(F_{22}+W_{x 22}\right)-M_{s 22}$;

$\left(m-m_{11}-m_{12}-m_{21}-m_{22}\right) \ddot{y}+\frac{1}{2} \beta_{y}\left(2\left(\dot{y}-\dot{y}_{1}\right)+2\left(\dot{y}-\dot{y}_{2}\right)\right)+$

$+4 c y y-\left(g_{0} m i_{s}\right) / \sqrt{i_{S}^{2}+1}=0$;

$m_{11} \ddot{x}_{11}-\beta_{x}\left(\dot{x}-\dot{x}_{11}\right)-c_{x}\left(x-x_{11}\right)=-F_{11}-W_{11}-W_{x 11}-Y_{11} \sin \gamma_{11}$;

$m_{12} \ddot{x}_{12}-\beta_{x}\left(\dot{x}-\dot{x}_{12}\right)-c_{x}\left(x-x_{12}\right)=-F_{12}-W_{12}-W_{x 12}-Y_{12} \sin \gamma_{12}$;

$m_{21} \ddot{x}_{21}-\beta_{x}\left(\dot{x}-\dot{x}_{21}\right)-c_{x}\left(x-x_{21}\right)=-F_{21}-W_{21}-W_{x 21}-Y_{21} \sin \gamma_{21}$;

$m_{22} \ddot{x}_{22}-\beta_{x}\left(\dot{x}-\dot{x}_{22}\right)-c_{x}\left(x-x_{22}\right)=-F_{22}-W_{22}-W_{x 22}-Y_{22} \sin \gamma_{22}$;

$m_{c} \ddot{z}_{c}-\beta_{c z}\left(\dot{z}-\dot{z}_{c}\right)-c_{c z}\left(z-z_{c}\right)=0 ; m_{c} \ddot{y}_{c}-\beta_{c y}\left(\dot{y}-\dot{y}_{c}\right)-c_{c y}\left(y-y_{c}\right)=0$;

$m_{c} \ddot{x}_{c}+\frac{1}{2}\left(-\frac{4 I_{z v} \dot{x}_{c} \dot{R}_{v}}{R_{v}^{3}}+\frac{2 I_{z v} \ddot{x}_{c}}{R_{v}^{2}}-\frac{4 I_{y b} \dot{x}_{c} \dot{R}_{p v}}{R_{p v}^{3}}+\frac{2 I_{y v} \ddot{x}_{c}}{R_{p v}^{2}}\right)+$

$+\frac{g_{0} m_{c}{ }^{i} p v}{\sqrt{i_{p v}^{2}+1}}-\beta_{c x}\left(\dot{x}-\dot{x}_{c}\right)-c_{c x}\left(x-x_{c}\right)=-m_{c} w_{v}$;

$b_{p}^{2} \sec ^{4} \theta\left(\beta_{z} \dot{\theta}+c_{z} \sin 2 \theta\right)+I_{x} \ddot{\theta}=0 ; a_{p}^{2} \sec ^{4} \varphi\left(\beta_{z} \dot{\varphi}+c_{z} \sin 2 \varphi\right)+I_{y} \ddot{\varphi}=0 ; ;$

$\frac{1}{2}\left(2 \sin \psi c_{z} a_{p}^{2}+2 \sin \psi c_{z} b_{p}^{2}\right)+I_{z} \ddot{\psi}=0 ; m_{o z} \ddot{z}_{o 11}+\beta_{o z} \dot{z}_{o 11}+c_{o z} z_{o 11}=N_{11}$;

$m_{o z} \ddot{z}_{o 12}+\beta_{o z} \dot{z}_{o 12}+c_{o z} z_{o 12}=N_{12} ; m_{o z} \ddot{z}_{o 21}+\beta_{o z} \dot{z}_{o 21}+c_{o z} z_{o 21}=N_{21}$;

$m_{o z} \ddot{z}_{o 22}+\beta_{o z} \dot{z}_{o 22}+c_{o z} z_{o 22}=N_{22}$;

$m_{m} \ddot{x}_{m 11}-\beta_{x m}\left(\dot{x}-\dot{x}_{m 11}\right)-c_{x m}\left(x-x_{m 11}\right)=Z_{11}\left(-F_{m 11}\right)$;

$m_{m} \ddot{x}_{m 12}-\beta_{x m}\left(\dot{x}-\dot{x}_{m 12}\right)-c_{x m}\left(x-x_{m 12}\right)=Z_{12}\left(-F_{m 12}\right)$;

$m_{m} \ddot{x}_{m 21}-\beta_{x m}\left(\dot{x}-\dot{x}_{m 21}\right)-c_{x m}\left(x-x_{m 21}\right)=Z_{21}\left(-F_{m 21}\right)$;

$m_{m} \ddot{x}_{m 22}-\beta_{x m}\left(\dot{x}-\dot{x}_{m 22}\right)-c_{x m}\left(x-x_{m 22}\right)=Z_{22}\left(-F_{m 22}\right)$. 
To evaluate quantitatively the effect of additional load on the efficiency of dynamic braking, numerical solution of the system of equations (1) was performed with the help of Wolfram Mathematica 8 software complex.

Objective of the modeling is to perform quantitative estimation of the braking process parameters.

Criterion of the braking system efficiency is as follows: capacity to stop the train of the specified mass within the braking path of the specified length (according to the current standards $-40 \mathrm{~m}$ for freight trains).

Input parameters are: train mass, railway track slope, degree of rail dirtiness.

Input parameters are: $M_{s 11}$ - braking torque on a wheel; $\psi$-coefficient of rail-wheel adhesion.

Measured parameters are: $\varepsilon_{x 11}$ - relative wheel slip taking a value within the range from zero (ideal wheel rolling along the rail without slip) up to a unit (wheel slip along the rail); $N_{11}$ - normal rail reaction under a wheel, $\mathrm{N} ; F_{11}-$ braking force at the point of wheel-rail contact, $\mathrm{N}$.

Output parameters are: $\dot{x}-$ locomotive velocity, $\mathrm{m} / \mathrm{s} ; x-$ locomotive travel along $O x$ axis (braking path), $\mathrm{m}$.

Research methodology includes following stages:

Stage 1 - determining parameters of the train braking process involving dynamic braking.

Stage 2 - determining parameters of the train braking process in terms of simultaneous use of dynamic braking and magnetic rail device to increase axial load.

Stage 3 - calculating train mass allowable for braking for the braking variants under comparison.

Stage 4 - evaluating the effect of the applied magnetic rail device to increase the locomotive axial loading upon the performance factor.

Stage 1. Modeling conditions are as follows: electric locomotive type is ARP10RV; train mass is $58 \mathrm{t}$; track slope is $35 \%$; initial braking velocity is $3 \mathrm{~m} / \mathrm{s}$; rails are covered with dirt; braking is of motor type.

Rail reaction under a wheel is specified with the value of $N_{11}=25000 \mathrm{~N}$ (Fig. 3b) corresponding to a quarter of the trailing weight of AРП10PB locomotive. If braking torque is increased up to $1147 \mathrm{~N} \cdot \mathrm{m}$, adhesion loss takes place being determined according to the value of relative wheel slip equal to a unit (Fig. 3b). Braking force on a wheel is growing during $2 \mathrm{~s}$ up to maximum value $F_{11}$ equal to $4450 \mathrm{~N}$; wheel lock-up results in sharp decrease in the braking force down to the value of $1640 \mathrm{~N}$ (Fig. 3d). As a result of the braking force drop, a locomotive starts moving with constant acceleration (Fig. 3e); finally, braking path exceeds considerably the specified value of $40 \mathrm{~m}$ (Fig. 3f).

Stage 2. Modeling conditions are as follows: electric locomotive type is ARP10RV; train mass is $58 \mathrm{t}$; track slope is $35 \%$; initial braking velocity is $3 \mathrm{~m} / \mathrm{s}$; rails are covered with dirt; braking is of motor type; additional vertical load is transmitted on the axis from the effect of a magnetic rail device.

While magnetic unit descending on the rail, additional vertical load $N_{F n i n}$ equal to $4000 \mathrm{n}$ was transmitted to a wheel; that resulted in the increased vertical reaction under the wheel (Fig. 4b) up to $29000 \mathrm{~N}$. The same torque as in the previous case was applied to a wheel (Fig. 4a); however, that was not resulted in wheel lock-up since relative wheel slip $\varepsilon_{x 11}$ was 0.008 (Fig. 4c). Braking force on a wheel over the whole braking period remained constant (about $4200 \mathrm{~N}$ ) that helped stop the train within the braking path equal to $30 \mathrm{~m}$ (Fig. 4f). 
$a$
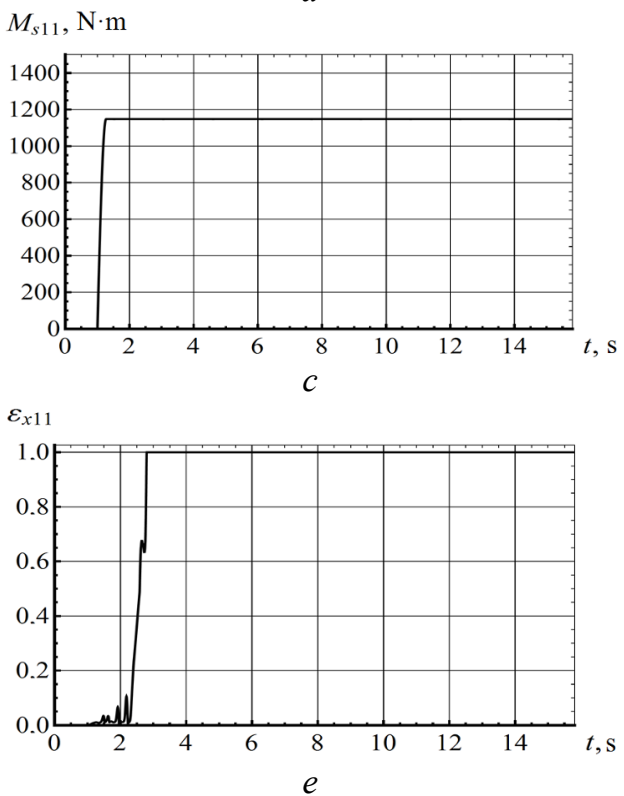

$x^{\prime}, \mathrm{m} / \mathrm{s}$

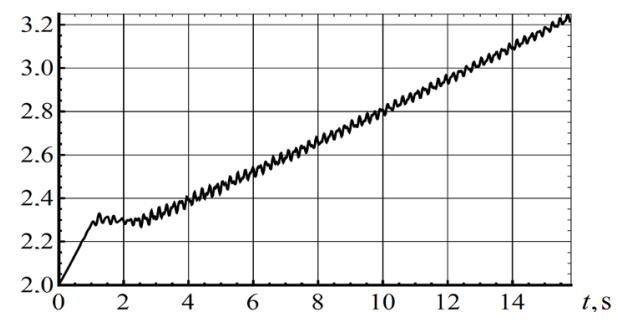

$b$
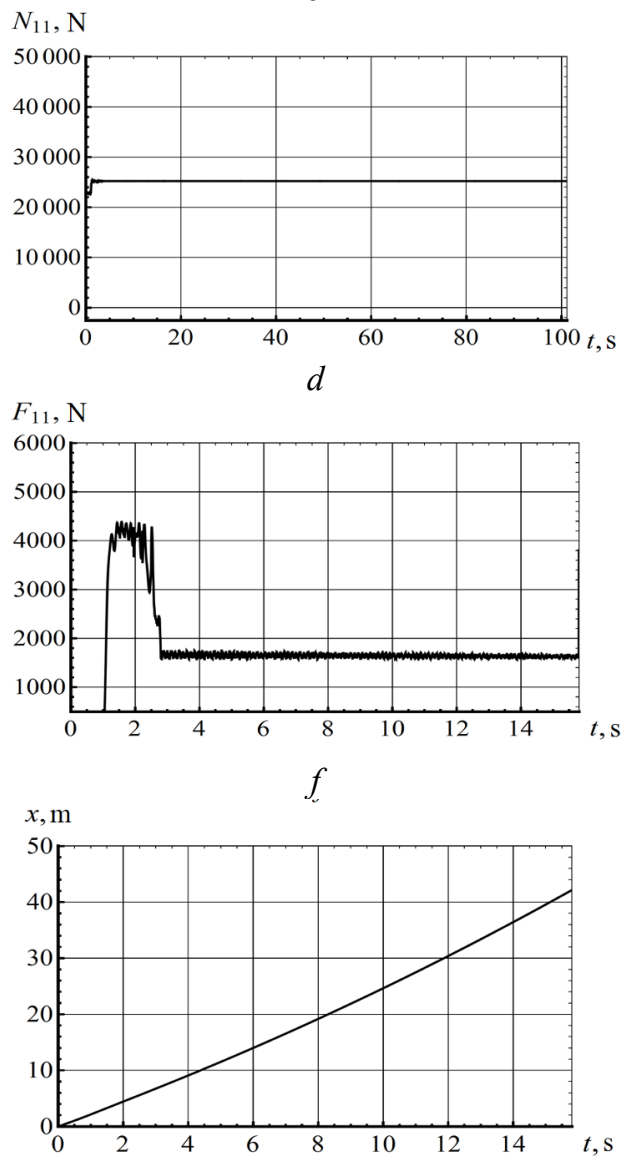

Fig. 3. Changes in the parameters of mine train braking process in terms of dynamic braking: $\mathrm{a}$ - braking torque on a wheel; $\mathrm{b}$ - rail reaction under a wheel; $\mathrm{c}$-relative wheel slip; $\mathrm{d}$-braking force on a wheel; $\mathrm{e}$ - locomotive velocity; $\mathrm{f}$ - braking path of a locomotive.

Similarly, braking process was modeled for different values of braking torque to determine maximum braking force according to the adhesion condition. Basing upon the modeling results, a graph of changes in braking force of a locomotive in terms of varying braking torque has been obtained for different variants of braking mechanisms (Fig. 5). Analysis of the graphs shows that while motor braking, rail reaction under a wheel is determined by the sum of values of vertical loads on a wheel from the trailing locomotive mass and dynamic constituents from the travels of the sprung mass of the locomotive underframe. In this case, when braking torque increases, braking force grows up to the value limited by the condition of the wheel-rail adhesion. If braking torque increases up to $M_{s . \max .1}$ value, there is the adhesion loss, locked-up wheels begin slipping along the rail (section II), braking force decreases by the value proportional to the difference of the value of adhesion and slip coefficients while increase in the braking torque after locking up does not result in the growth of braking force. 
$a$
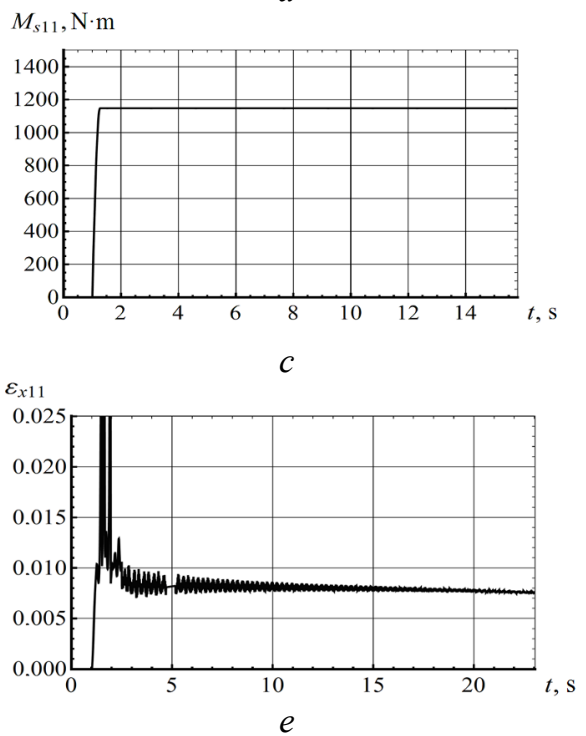

$x^{\prime}, \mathrm{m} / \mathrm{s}$

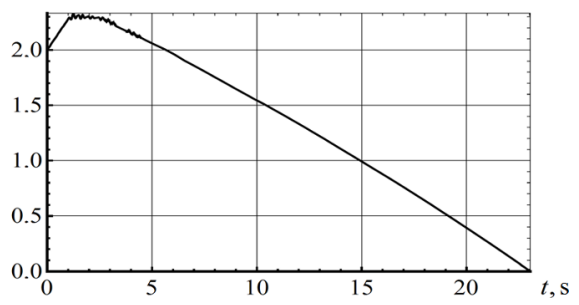

$b$
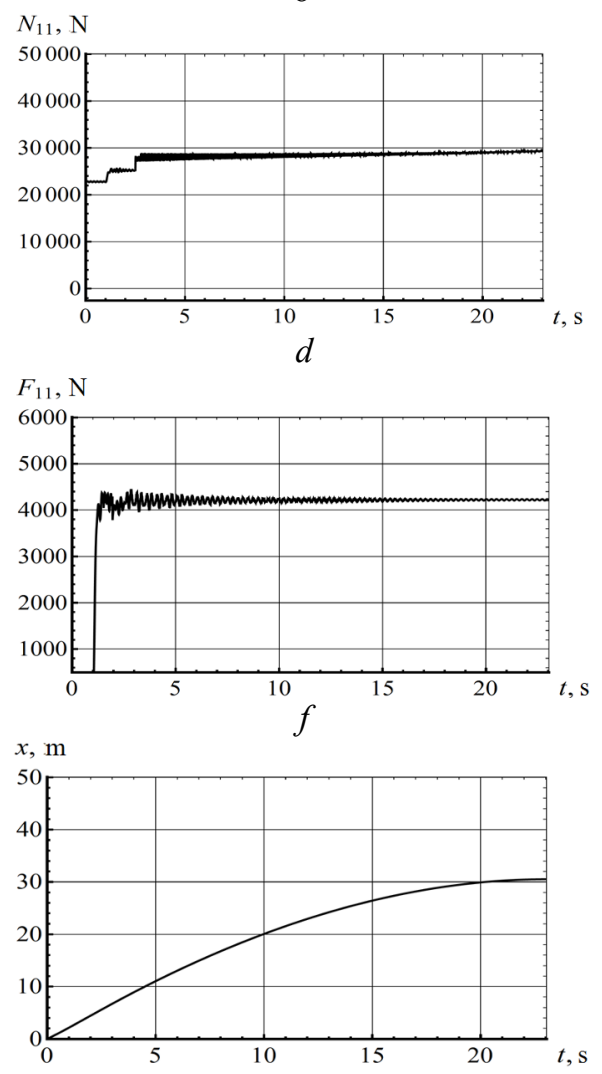

Fig. 4. Changes in the parameters of mine train braking process in terms of simultaneous use of dynamic braking and a magnetic rail device: $\mathrm{a}$ - braking torque on a wheel; $\mathrm{b}$ - rail reaction under a wheel; $\mathrm{c}$ - relative wheel slip; $\mathrm{d}$ - braking force on a wheel; e-locomotive velocity; $\mathrm{f}$ - braking path of a locomotive.

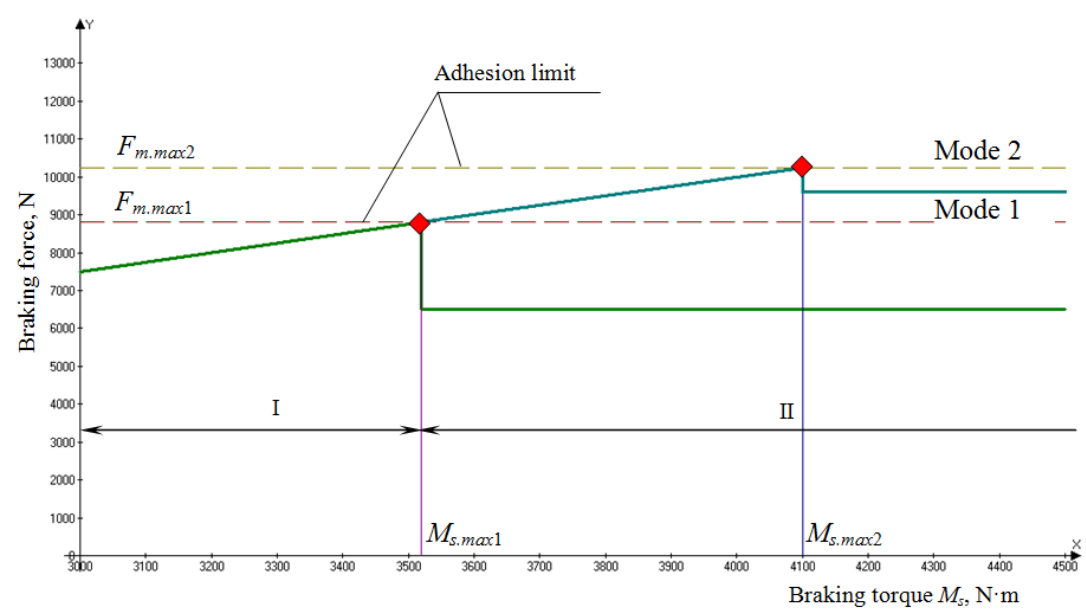

Fig. 5. Graph of the dependence of braking force on the locomotive wheels upon the braking torque value: mode 1 -motor braking without additional wheel load; mode 2 -motor braking with the additional wheel load from the effect of a magnetic rail device; $\diamond$ - point of adhesion loss; straight line 1 - adhesion limit for mode 1 ; straight line 2 - adhesion limit for mode 2. 
While using a magnetic rail device, a share of the magnetic attraction force of a braking unit is transmitted onto the locomotive axes; due to that, rail reaction under a wheel increases. Within section I, additional wheel load does not result in changes in braking force $F_{11}$; the effect is demonstrated in the increased stability of the locomotive underframe in the rail gage. Within section II, law of changes in braking force will be determined by the product of wheel load by the friction coefficient of wheel slip along the rail; however, in this case, rail reaction under a wheel will be higher by the additional load value - consequently, friction force of a wheel along the rail will be higher as well.

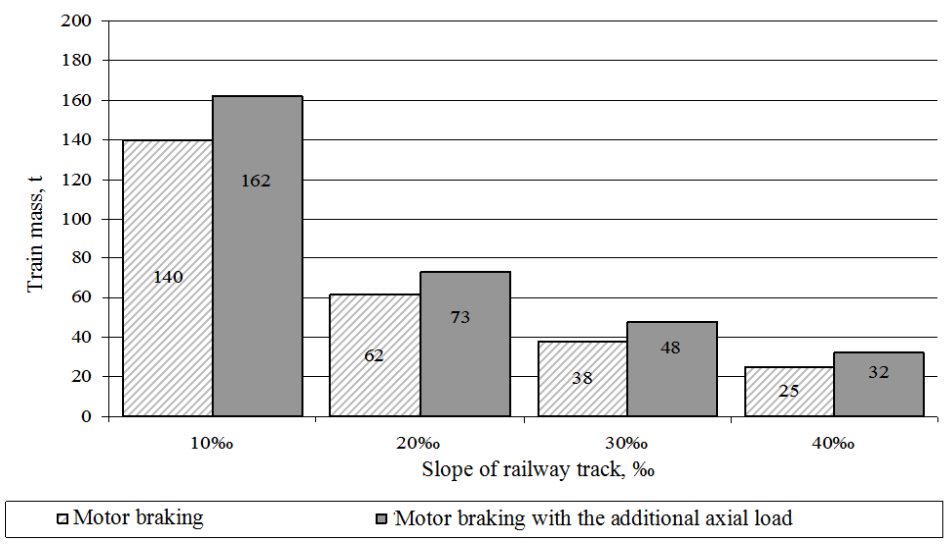

Fig. 6. Calculation results of the train mass allowable for braking in terms of different combinations of breaking mechanisms.

Calculations performed according to methodology [8] have demonstrated that increase in braking characteristics of a locomotive at the expense of transmitted additional axial load makes it possible to increase the train mass allowable for braking (Fig. 6); moreover, relative train mass increment is more distinct when locomotive operates within the mine workings with greater track slopes. Thus, if slope is $10 \%$, train mass increment will be $22 \mathrm{t}$ $(16 \%)$; if slope is $30 \%$, mass increment will be $10 \mathrm{t}(24 \%)$; and if slope is $40 \%$, mass increment will be $7 \mathrm{t}(29 \%)$.

\section{Conclusions}

The research solves topical problem of the increase in train mass allowable for braking by means of the growing efficiency of service braking in terms of simultaneous use of dynamic braking and a magnetic rail device.

Following results have been obtained:

1) mathematical model of the braking process of a mine train in terms of simultaneous use of standard braking mechanisms and a magnetic rail device to increase axial load have been developed;

2) braking process for real operating conditions has been modeled; it has been determined that the additional axial load transmitted from a magnetic rail device to increase axial load helps improve the value of safe (in terms of wheel lock-up) braking torque by $15 \%$ making it possible to implement greater braking force on a wheel;

3) quantitative evaluation of the effect of additional load and resulting indices of the locomotive transport operation has been performed. It has been specified that the use of rail magnetic device makes it possible to increase train mass allowable for braking by $16-29 \%$ depending upon the railway track slope. 
This work was conducted within the projects "Theoretical substantiation of technical solutions to improve the performance characteristics of mine wheeled transport" (State registration No. 0105U009159).

\section{References}

1. Pivnyak, G.G., Sakhno, V.P., Kravets, V.V., \& Bas, K. M. (2019). Method for determining highspeed vehicle contact forces of the ground transport. Naukovyi Visnyk Natsionalnoho Hirnychoho Universytetu, (1), 55-61. https://doi.org/10.29202/nvngu/2019-1/8

2. Zabolotny, K., \& Panchenko, E. (2010). Definition of rating loading in spires of multilayer winding of rubberrope cable. New Techniques and Technologies in Mining - Proceedings of the School of Underground Mining, 223-229. https://doi.org/10.1201/b11329-38

3. Taran, I.A. (2012). Interrelation of circular transfer ratio of double-split transmissions with regulation characteristic in case of planetary gear output. Naukovyi Visnyk Natsionalnoho Hirnychoho Universytetu, (3), 75-85.

4. Taran, I., \& Bondarenko, A. (2017). Conceptual approach to select parameters of hydrostatic and mechanical transmissions for wheel tractors designed for agrucultural opeations. Archives of Transport, 41(1), 89-100. https://doi.org/10.5604/01.3001.0009.7389

5. Ilin, S.R., Samusya, V.I., Kolosov, D.L., Ilina, I.S., \& Ilina, S.S. (2018). Risk-forming dynamic processes in units of mine hoists of vertical shafts. Naukovyi Visnyk Natsionalnoho Hirnychoho Universytetu, (5), 64-71. https://doi.org/10.29202/nvngu/2018-5/10

6. Taran, I., \& Klymenko, I. (2013). Transfer ratio of double-split transmissions in case of planetary gear input. Naukovyi Visnyk Natsionalnoho Hirnychoho Universytetu, (6), 60-66.

7. Franchuk, V.P., Ziborov, K.A., Krivda, V.V., \& Fedoriachenko, S.O. (2018). Influence of thermophysical processes on the friction properties of wheel - rail pair in the contact area. Naukovyi Visnyk Natsionalnoho Hirnychoho Universytetu, (2), 46-52. https://doi.org/10.29202/nvngu/2018-2/7

8. SOU 10.1.001.85790.007 (2006). Transport shakhtnyy lokomotyvnyy. Perevezennya lyudey $i$ vantazhiv $v$ vyrobkakh $z$ ukhylom koliyi vid 0,005 do 0,050. Kyiv: Ministerstvo vuhilnoi promyslovosti Ukrainy.

9. Lee, N.-J., \& Kang, C.-G. (2016). Wheel slide protection control using a command map and Smith predictor for the pneumatic brake system of a railway vehicle. Vehicle System Dynamics, 54(10), 1491-1510. https://doi.org/10.1080/00423114.2016.1213864

10. Wanve, S, Malode, A. \& Ghonmode, N. (2017). An analysis for improving performance of train brake pad by using CAD and CAE software. International Research Journal of Engineering and Technology, (4), 1174-1175.

11. Galardi, E., \& Meli, E. \& Nocciolini, D. (2015). Galardi, E., Meli, E., Nocciolini, D., Pugi, L., \& Rindi, A. (2015). Development of efficient models of Magnetic Braking Systems of railway vehicles. International Journal of Rail Transportation, 3(2), 97-118. https://doi.org/10.1080/23248378.2015.1015219

12. Protsiv, V.V. (2011). Nauchnoe obosnovanie novykh tekhnicheskikh resheniy po sovershenstvovaniyu tormoznoy sistemy shakhtnogo sharnirno-sochlenennogo lokomotiva. $\mathrm{PhD}$ Thesis. Dnipropetrovsk, Ukraine: NGU.

13. Husain, A. (2013). Dynamic Braking Control for Accurate Train Braking Distance Estimation under Different Operating Condtions. PhD Thisis. Blacksburg. USA: Polytechnic Institute and State University.

14. Sharma, R.C., Dhinga, M., \& Pathak, R.K. (2015). Braking Systems in Railway Vehicles. International Journal of Engineering \& Technology (IJERT), 4(1), 206-211.

15. Kitanov, S., \& Podol'skii, A. (2008). Analysis of Eddy-Current and Magnetic Rail Brakes for High-Speed Trains. The Open Transportation Journal, 2(1), 19-28. https://doi.org/10.2174/1874447800802010019 
16. Liudvinavičius, L., \& Lingaitis, L. (2007). Electrodynamic braking in high speed rail transport. Transport, 22(3), 178-186. https://doi.org/10.1080/16484142.2007.9638122

17. Tran, M.T., \& Keng Ang, K. (2016). High-speed trains subject to abrupt braking. Vehicle System Dynamics, 54(12), 1715-1735. https://doi.org/10.1080/00423114.2016.1232837

18. Yang, Y., Xiong, L., Liu, W., Gao, K., \& Huang, Z. (2018). An Energy-Based Nonlinear Pressure Observer for Fast and Precise Braking Force Control of the ECP Brake. International Journal of Precision Engineering and Manufacturing, 19(10), 1437-1445. https://doi.org/10.1007/s12541$\underline{018-0170-4}$

19. Piechowiak, T. (2010). Verification of pneumatic railway brake models. Vehicle System Dynamics, (48), 283-299.

20. Ma, J., Zhang, B., Huang, X., Fang, Y., \& Cao, W. (2011). Design and analysis of the hybrid excitation rail eddy brake system of high-speed trains. Journal of Zhejiang University-SCIENCE A, 12(12), 936-944. https://doi.org/10.1631/jzus.a11gt002

21. Novytskyi, O.V., Taran, I.O., \& Protsiv, V.V. (2005). Device for increasing the load on the axles of a rail vehicle. Patent No. 7B61C, Ukraine.

22. Protsiv, V.V., Novytskyi, O.V. \& Samoilov, A.I. (2012). Perevahy mahnitoreikovoho dovantazhuvacha nad reikovym halmom u shakhtnomu lokomotyvi. Naukovyi Visnyk Natsionalnoho Hirnychoho Universytetu, (4), 79-84.

23. Otrosh, Y., Kovalov, A., Semkiv, O., Rudeshko, I., \& Diven, V. (2018). Methodology remaining lifetime determination of the building structures. MATEC Web of Conferences, (230), 02023. https://doi.org/10.1051/matecconf/201823002023

24. Oprea, R.A., Cruceanu, C., \& Spiroiu, M.A. (2013). Alternative friction models for braking train $\begin{array}{llll}\text { dynamics. } & \text { Vehicle System } & \text { Dynamics, } & \text { 51(3), }\end{array}$ https://doi.org/10.1080/00423114.2012.744459

25. Ursulyak, L.V., \& Shvets, A.O. (2017). Improvement of mathematical models for estimation of train dynamics. Nauka ta Progres Transportu, 6(72), 70-77. https://doi.org/10.15802/stp2017/118002

26. Protsiv, V.V., \& Monya, A.G. (2003). Eksperimental'noe opredelenie kharakteristik stsepleniya shakhtnogo lokomotiva $\mathrm{v}$ rezhime tormozheniya. Metallurgicheskaya $i$ Gornorudnaya Promyshlennost', (8), 95-97. 